\title{
Anteroposterior dentoalveolar effects with cervical headgear and pendulum appliance: a systematic review
}

\author{
Ana de Lourdes Sá de Lira', Antonio Izquierdo', Sávio Prado', Matilde Nojima², Lucianne Maia² \\ 'DDS, MS, PhD student, Department of Orthodontics, Dental School, Federal University of Rio de Janeiro, RJ, Brazil \\ ${ }^{2}$ DDS, PhD, Professor, Department of Orthodontics, Dental School, Federal University of Rio de Janeiro, RJ, Brazil
}

\begin{abstract}
Aim: The aim of this systematic review was to compare the maxillary dental effects of cervical headgear and pendulum appliance during distalization of permanent maxillary first molars. Methods: A literature survey from databases covering the period from 1956 to August 2008 was carried out. Randomized controlled trials (RCT) and controlled clinical trials (CCT) were included. Two reviewers selected and extracted the data independently, and also assessed the quality of the retrieved studies. Results: The search strategy resulted in 48 articles, of which 3 met the inclusion criteria. Distal molar movement with headgear versus pendulum appliance was identified. In all studies selected, the methods used to detect and analyze the distal molar movement were valid and generally well know. All articles included an error analysis method and considered the risk for confounding factors, but only one study used blinding in measurements. Conclusions: The studies showed that both cervical headgear with patient compliance and a non-compliance pendulum appliance are very effective in distalizing maxillary molars. However, additional RCTs with larger samples of both molar distalizing appliances are needed to confirm this result and provide further reliable scientific evidence.
\end{abstract}

Keywords: distal molar movement, cervical traction, pendulum appliances.

\section{Introduction}

Received for publication: May 02, 2012

Accepted: June 08, 2012

Correspondence to: Ana de Lourdes Sá de Lira Departamento de Ortodontia,

Faculdade de Odontologia,

Universidade Federal do Rio de Janeiro Av. Brigadeiro Trompowsky s/n, CEP: 21941-590

Ilha do Fundão, RJ, Brasil E-mail: anadelourdess।@ hotmail.com
Maxillary molars can be distally shifted towards a Class I position during the non-extraction treatment of Class II malocclusion in order to obtain enough space for the orthodontic retention of canines, incisors and premolars. For example, distalization can be achieved by using extra-oral traction appliances ${ }^{1}$ or intraoral devices such as pendulum appliances ${ }^{2-4}$ and superelastic coils. ${ }^{5,6}$.

Headgear (HG) is effective in maxillary molar distalization, but it depends greatly on patient cooperation ${ }^{1}$, and its is often unsatisfactory for some patients from a clinical point of view. Consequently, several distalizing appliances have been suggested in literature, such as a pendulum appliance $(\mathrm{P})$, which is a toothtissue-borne appliance that includes a Nance button on the palate for intraoral anchorage and titanium-molybdenum coils, which deliver a mild and continuous force to the maxillary molars. ${ }^{2}$

A number of studies on the usage, function and effectiveness of different types of molar distalizing appliances have been published despite the difficulty 
in certain clinical orthodontic applications for some of these devices. In addition, there is great variability in study designs, sample size and type of research. Currently, evidence-based studies have been accepted for publication as the systematic research review allows identification, selection and evaluation to be critically performed ${ }^{7,8}$.

There are numerous modifications of the Hilgers 9 pendulum that are completely different in terms of biomechanics $^{10-12}$.

The literature is vast on studies concerning different molar distalizing appliances in terms of application, function and effectiveness. However, it can be difficult for the orthodontist to interpret the outcomes of these studies because of the variety of study designs, sample sizes and research approaches.

The present systematic review aimed to compare the maxillary dental effects of cervical headgear and pendulum appliance during distalization of permanent maxillary first molars.

\section{Materials and methods}

\section{Search strategy}

The strategy for undertaking this systematic review was mainly influenced by the National Health Service, NHS, Center for Reviews and Dissemination. ${ }^{13}$ To identify all original research studies that examined orthodontic systems for maxillary molar distalization and dental changes, a literature search was carried out in the Medline database (Entrez Pub Med, www.ncbi.nim.nih.gov) Ovid, Cochrane Collaboration Oral Health Group Database of Clinical Trials (www.cochrane.org), Web of Science, Google Scholar Beta, Embase, Extenza, Evidence-Based medicine, American and Caribbean Center on Health Sciences Information and BIREME, covering the period from 1956 to August (Table 1). The key-words were: Distal molar movement; Cervical traction; Class II malocclusion; Pendulum appliance.

Table 1: Search strategy for systematic review

\begin{tabular}{lc}
\hline Step & Cearch terms \\
$\# 1$ & Extraoral traction appliance\$ \\
$\# 2$ & $(\# 1)$ OR (\#2) \\
$\# 3$ & Pendulum appliance\$ \\
$\# 4$ & K-loop\$ \\
$\# 5$ & $(\# 4)$ OR (\#5) \\
$\# 6$ & $(\# 3)$ AND (\#6) \\
$\# 7$ & Limit 7 to humans \\
$\# 8$ & Randomized controlled Trial\$ \\
$\# 9$ & Controlled clinical trial\$ \\
$\# 10$ & $(\# 8)$ AND (\#9) \\
$\# 11$ & $(\# 8)$ AND (\#10) \\
$\# 12$ & $(\# 11)$ OR (\#12) \\
$\# 13$ &
\end{tabular}

\section{Selection criteria}

For the inclusion criteria, human studies, randomized controlled trials (RCTs) and controlled clinical trials (CCTs) comparing the two molar distalizing appliances were selected. The samples consisted of both male and female individuals presenting Class II malocclusions in either permanent or mixed dentition, during growth spurt and as long as there had been no orthodontic extractions before distalization. Extraoral or pendulum appliances had to be used for molar distalization. Prospective and retrospective studies, case reports, abstracts, review articles, animal studies, in vitro studies, letters and technical comments on any type of distalizing appliance were all excluded. A study of the full text was carried out if at least one of the two reviewers considered it to be potentially relevant.

A total of 48 original research studies were thus selected. After initial selection, articles were read and those that met the inclusion criteria were carefully analyzed (Figure 1). The searches were complemented by screening the references of selected articles to find any that did not appear in the database search.

The reference lists of the retrieved articles were also checked for additional studies. Two reviewers independently assessed the articles with respect to the inclusion and exclusion criteria and the Kappa score measuring the level of agreement was 0.92 (very good). ${ }^{14}$ Any interexaminer conflicts were resolved by discussion to reach consensus.

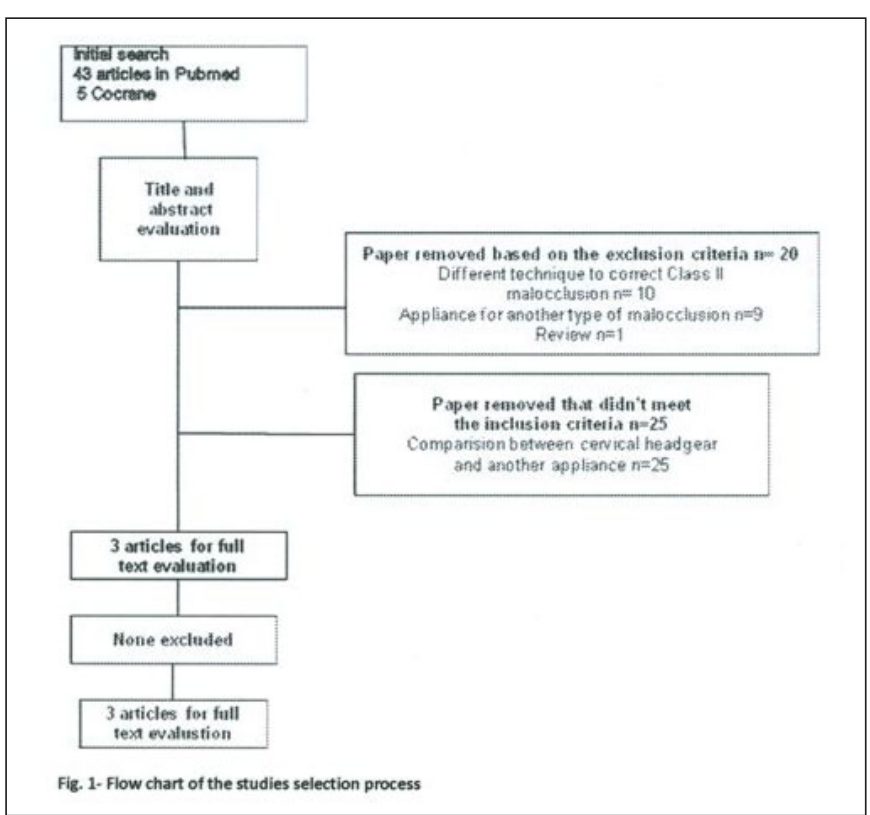

Fig. 1. Flowchart of the study selection process.

\section{Data collection and analysis}

The following data were gathered: article title, author, year of publication, type of study, materials, gender, age, treatment length, type of distalizing appliance, cervical headgear $(\mathrm{CH})$ or pendulum appliance $(\mathrm{P})$, cephalometric values of dental changes before and after orthodontic treatment and differences between the two modalities. The qualitative evaluation of the methodology applied to the articles was in accordance with those described by Antczak et al ${ }^{15}$ and Jadad et $\mathrm{al}^{16}$. The following eight variables were assessed: type of study $(\mathrm{RCT})=3$ points; $(\mathrm{CCT})=2$ points; sample size of whole study $\geq 30$ subjects $=1$ point; adequate 
description of the sample screening method $=1$ point; methodological coherence $=1$ point; use of error analysis method = 1 point; blinded measurements = 1 point; adequate statistical tests $=1$ point and confounding factors $=1$ point. Each article, therefore, could reach a maximum score of 10 points, and they were rated as: below average (score ranging from 0 to 5 points); mean average (score ranging from 6 to 8 points) and above average (score ranging from 9 to 10 points).

The data extraction and quality scoring from each article were assessed independently by two evaluators and without blinding. Interexaminer conflicts were resolved by discussion of each article to reach a consensus. The Kappa scores for levels of agreement between the two reviewers are shown in Table 2 .

Table 2. Kappa scores Measuring Levels of Agreement between the two reviewers in assessing data and Quality Scores of the included articles

\begin{tabular}{lcl}
\hline & Kappa Value & Level of Agreement \\
Study design & 1.0 & Very good \\
Sample size & 0.8 & Good \\
Selection description & 1.0 & Very good \\
Valid measurement methods & 1.0 & Very good \\
Method error analysis & 1.0 & Very good \\
Bliding in measurements & 0.8 & Good \\
Adequate statistic provided & 1.0 & Very good \\
Confounding factors & 0.82 & Very good \\
Judged quality standard & 0.92 & Very good \\
\hline Kappa values- $0.20=$ poor, $0.21-0.40=$ fair, $0.41-0.60=$ moderate, $0.61-0.80$ \\
$=$ Good, $0.81-1.0=$ very good.
\end{tabular}

\section{Results}

The search yielded 48 results according to inclusion and exclusion criteria and 3 articles were selected for final analysis: two CCTs and one RCT. In these 3 articles, the maxillary second molars were unerupted. The force exerted with cervical headgear ${ }^{1}$ was $500 \mathrm{~g}$ with an average use of 14$16 \mathrm{~h}$ per day until a Class I molar relationship was achieved and pendulum appliance, as described by Hilgers ${ }^{2}$ was used. It consisted of an acrylic Nance portion with an expansion screw and two posteriorly extending TMA coil springs that were inserted into the lingual sheaths on the first molar bands. The appliance was anchored to the first and second premolars with wires bonded to the occlusal surfaces. The pendulum springs were activated parallel to the palatal midline, with a mean force of about $250 \mathrm{~g}$, following the activation scheme suggested by Hilgers. ${ }^{2}$

The measurements were taken before the patients were treated with fixed appliances and the values given refer to changes after the first phase of treatment, except in the Mossaz et al study, where final measurements were taken after active treatment. There was not an untreated Class II group (control group) for comparison in this work. However the first and the second studies were CCT and the third study was RCT and in all the studies, the pendulum appliance and cervical traction appliance were compared between themselves. Also in the third study the sample was randomly divided into two groups, $\mathrm{P}$ group and $\mathrm{CH}$ group.

\section{Comparing the two distalization techniques}

In the study by Tanner et al. ${ }^{10}$, the maxillary superimposition was performed on the palatal plane registered at ANS. The dental measurements were obtained through maxillary superimposition, thereby eliminating the orthopedic changes of the maxilla during the experimental period. The long axes of the maxillary first and second molars were constructed by drawing a line through the mesiobuccal cusp tip and the mesiobuccal root apex, whereas the long axis of the first premolar tooth was constructed through the buccal cusp tip and the apex. The long axis of the incisor tooth was constructed through the incisal edge and the apex. The angular differences in tooth position due to first molar distalization were then measured as the angles between the long axes of each maxillary tooth at T1 (before first molar distalization) and T2 (after first molar distalization). The distances between the most convex distal points on the crowns of first molar and first premolars at $\mathrm{T} 1$ and $\mathrm{T} 2$, which were measured on a line parallel to the palatal plane, were used to determine the amount of molar distalization. The vertical movements of teeth were determined by measuring the perpendicular distances between the mesiobuccal cusp tip of the molar and incisal edge of the incisor teeth relative to the palatal plane.

Tanner et $\mathrm{al}^{10}$ showed that the mean amount of distalization was $3.15 \pm 1.94 \mathrm{~mm}$ for the $\mathrm{CH}$ group and 3.81 $\pm 2.25 \mathrm{~mm}$ for the P group, but the mean difference between them was not significant. The first premolars moved mesially in the P group (mean $-0.73 \pm 3.53 \mathrm{~mm}$ ) and distally in the $\mathrm{CH}$ (mean $1.88 \pm 1.12 \mathrm{~mm}$ ) with significance $P<.01$. The incisors were proclined a mean of $6.08 \pm 3.67^{\circ}$ in the $\mathrm{P}$ group and $1.73 \pm 3.12^{\circ}$ in the $\mathrm{CH}$ group with significance $P$ $<0.01$. The mean sagittal change in incisor position was $0.42 \pm 1.59 \mathrm{~mm}$ for $\mathrm{CH}$ and $2 \pm 1.54 \mathrm{~mm}$ for the P group, but the mean difference was not statistically significant. The mean value of the first molar extrusion in the $\mathrm{CH}$ group was $1.42 \pm 0.98$, whereas in the $\mathrm{P}$ group it was $0.00 \pm 0.96$, being significantly different between groups $(\mathrm{P}<.01)$. The differences in the mean values of the vertical position of the first premolar and the incisor were not statistically different between the groups (Table 3 ).

In Mossaz et al's study, at T1 (before molar distalization) radiograph, an x-y cranial base coordinate was constructed through the sella with the horizontal $\mathrm{x}$-axis drawn at $7^{0}$ to the sella-nasion line and the vertical $y$-axis passing through the anterior wall of the sella perpendicular to the $\mathrm{x}$-axis. The points were transferred to the final head film at T2 (after fixed appliance therapy) after superimposition on the cranial base stable structures. Maxillary incisor, mandibular incisors and molar tip were measured.

Mossaz et $\mathrm{al}^{11}$ found $5.08^{0}$ an average of maxillary first molar tip back for the $\mathrm{CH}$ group and $1.98^{\circ}$ an average for the $\mathrm{P}$ group, being statistically significant $(P<.001)$. Maxillary incisor torque control was adequate in both groups $\left(5^{0}\right.$ in the $\mathrm{CH}$ group and $2.3^{\circ}$ in the $\mathrm{P}$ group), whereas the mandibular 
Table 3. Summarized data of three studies concerning two molar distalization appliances

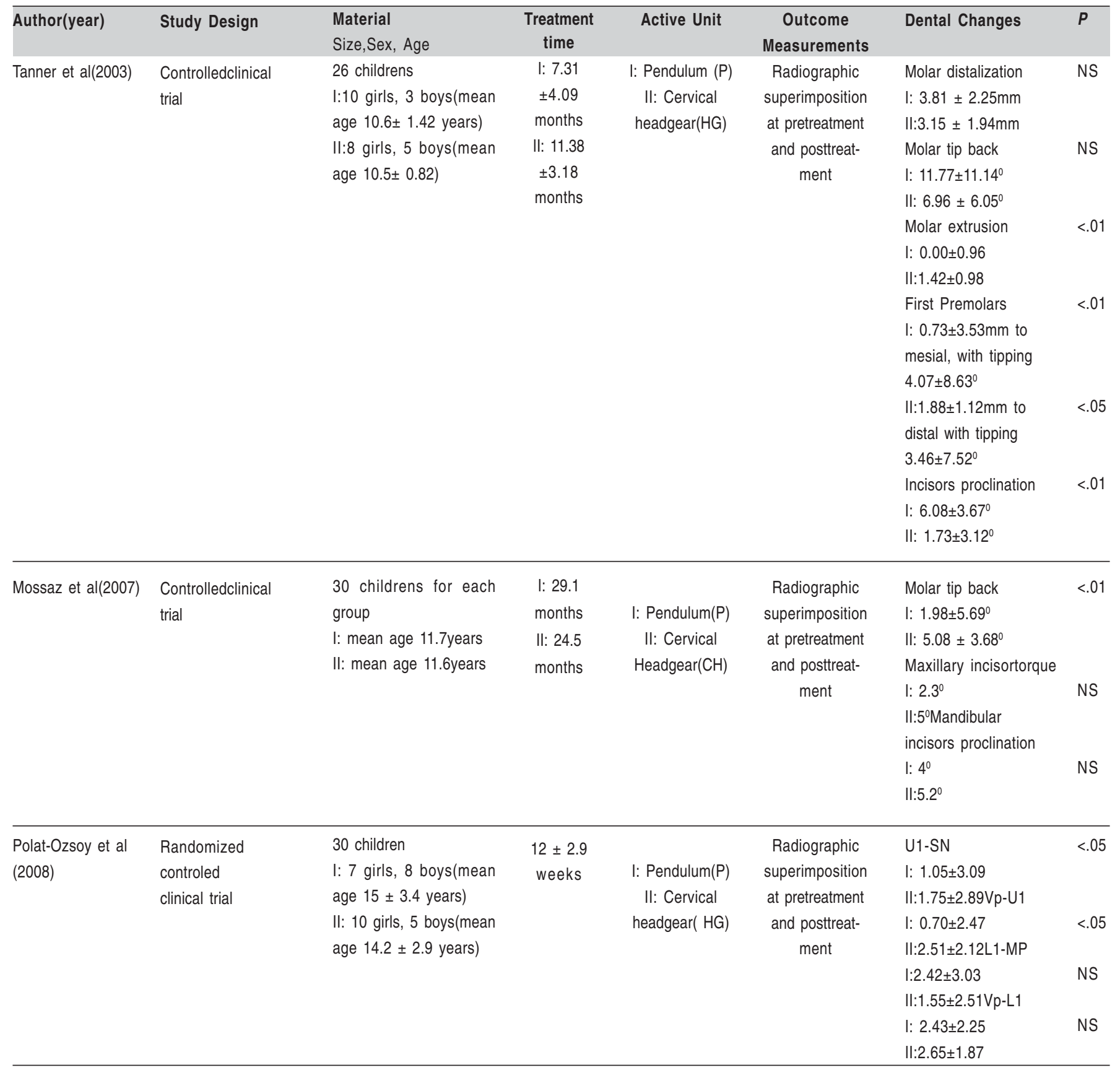

incisors were proclined in both groups $\left(5.2^{0}\right.$ in the $\mathrm{CH}$ group and $4^{0}$ in the $\mathrm{P}$ group) but the mean difference between them was not significant in either measurement (Table 3).

In the study by Polat-Ozsoy ${ }^{12}$, the cephalograms at $\mathrm{T} 1$ (before molar distalization) and T2 (after first molar distalization) were traced. Two coordinate systems, related to the cranial base and maxilla, were established: a CT horizontal reference plane passing through the $\mathrm{C}$ point (the most anterior point of the cribriform plate at the junction with the nasal bone) and point $\mathrm{T}$ (the most superior point of the anterior wall of the sella turcica at the junction with the tuberculum sella). A vertical reference plane (Vp) was constructed perpendicular to the CT horizontal reference line at the $\mathrm{T}$ point. U1-SN angle, L1-MP angle, Vp-U1 (distance from vertical plane to maxillary incisor crown tip) and VpL1 (distance from vertical plane to lower incisor crown tip).

Polat-Ozsoy et $\mathrm{al}^{12}$ observed a decrease in the U1-SN angle and $\mathrm{Vp}-\mathrm{U} 1$ distance in the $\mathrm{CH}$ group greater than in the $\mathrm{P}$ group, showing a statistically significant $(P<.05)$. The pendulum appliance seemed to have no significant effect on the maxillary incisor position. Lower incisors were retruded in both groups, but there was no significant difference between them (Table 3).

\section{Quality of the studies}

A quality analysis of the 3 studies involved is summarized in Table 4. The research quality and methodological soundness were high in last study, ${ }^{12}$ medium 
Table 4. Quality evaluation of the 3 involved studies

\begin{tabular}{|c|c|c|c|c|c|c|c|c|c|}
\hline $\begin{array}{l}\text { Autor } \\
\text { (year) }\end{array}$ & $\begin{array}{l}\text { Study } \\
\text { Design }\end{array}$ & $\begin{array}{l}\text { Sample } \\
\text { Size }\end{array}$ & $\begin{array}{c}\text { Selection } \\
\text { Description }\end{array}$ & $\begin{array}{c}\text { Valid } \\
\text { Measurement }\end{array}$ & $\begin{array}{l}\text { Method } \\
\text { Error }\end{array}$ & $\begin{array}{c}\text { Blindingin } \\
\text { Measurements }\end{array}$ & $\begin{array}{l}\text { Adequate } \\
\text { Statistic }\end{array}$ & $\begin{array}{l}\text { Confounding } \\
\text { Factors }\end{array}$ & $\begin{array}{l}\text { Judged } \\
\text { Quality } \\
\text { Standard }\end{array}$ \\
\hline $\begin{array}{l}\text { Tanner } \\
\text { et al (2003) }\end{array}$ & $\begin{array}{l}\text { Controlled } \\
\text { clinical trial } \\
\text { prospective }\end{array}$ & Inadequate & Inadequate & $\begin{array}{c}\text { Methods } \\
\text { Yes }\end{array}$ & $\begin{array}{c}\text { Analysis } \\
\text { Yes }\end{array}$ & No & $\begin{array}{c}\text { Provided } \\
\text { Yes }\end{array}$ & $\begin{array}{l}\text { Yes,different } \\
\text { kinds of } \\
\text { molardistalization } \\
\text { appliances, } \\
\text { patients in growth } \\
\text { spurt, patient } \\
\text { compliance and } \\
\text { greatertreatment } \\
\text { time with the } \\
\text { cervicalheadgear }\end{array}$ & $\begin{array}{c}\text { Below } \\
\text { average }\end{array}$ \\
\hline $\begin{array}{l}\text { Polat-Ozsoy } \\
\text { et al (2008) }\end{array}$ & $\begin{array}{l}\text { Randomized } \\
\text { controlled } \\
\text { clinical }\end{array}$ & Adequate & Adequate & Yes & Yes & Yes & Yes & $\begin{array}{l}\text { Yes,differentkinds of } \\
\text { molardistalization } \\
\text { appliances,patients } \\
\text { ingrowth spurt } \\
\text { and patient } \\
\text { compliance } \\
\text { with the cervical } \\
\text { headgear }\end{array}$ & $\begin{array}{l}\text { Above } \\
\text { average }\end{array}$ \\
\hline
\end{tabular}

in second study ${ }^{11}$ and low in first one. ${ }^{10}$ In all studies selected, ${ }^{10-12}$ the methods used to detect and analyze the dental movement were valid and generally well know. All included an error analysis method and just the last study ${ }^{12}$ used blinding in measurements (Table 4).

\section{Discussion}

Initially, 33 RCTs and twelve CCTs studies of distalizing appliances for maxillary molars were excluded. The kappa scores for levels of agreement between the two reviewers in assessing data extraction and quality scores of the included articles were in the range of good to very good, thus indicating that the results are reliable (Table 2).

All studies ${ }^{10-12}$ showed a heterogeneity, which means that it was difficult to combine data and draw any consistent conclusions from these studies. It was difficult to compare the studies about dental changes during maxillary first molar distalization because the cephalometric methods used to measure the amount of distalization were different.

For example, the first one ${ }^{10}$ suggested that both the cervical headgear and the pendulum appliance were capable of distalizing molars similar amounts. It means that there was not a significant difference between them. It was observed that the values were indeed close to each other, $3.15 \mathrm{~mm}$ with the cervical headgear and $3.81 \mathrm{~mm}$ with the pendulum appliance, but the mean treatment time was $11.38 \pm 3.18$ months for the $\mathrm{CH}$ group and $7.31 \pm 4.09$ months for $\mathrm{P}$ group. These findings were in agreement with those of other authors ${ }^{3,4,17}$. Maxillary first molars were tipped distally in both groups. Even though $11.04^{\circ}$ of distal tipping was accomplished rapidly in the $\mathrm{P}$ group, it was not statistically different from the $6.96^{\circ}$ of distal tipping achieved in the $\mathrm{CH}$ group. These findings are in agreement with those of Cook et al, ${ }^{17}$ Ghosh and Nanda, ${ }^{3}$ Byloff and Darendeliler ${ }^{4}$ and Byloff et all ${ }^{5}$. The mean extrusion of $1.42 \mathrm{~mm}$ in first molar position in the $\mathrm{CH}$ group and vertically stable position in the $\mathrm{P}$ group are in agreement with Ghosh and Nanda. ${ }^{3}$ However, the difference in treatment time between the two groups could have an effect on first vertical position.

Taner et $\mathrm{al}^{10}$ showed that spontaneous distalization of premolars due to molar distalization with $\mathrm{CH}$ was an expected outcome in most instances. But in the $\mathrm{P}$ group the anchorage loss of the first premolar was observed. The mesial movement was $0.73 \mathrm{~mm}$ with $4^{0}$ of mesial tipping associated to significant incisor proclination. Similar results were found by Ghosh and $\mathrm{Nanda}^{3}$. Although both the pendulum appliance and cervical headgear are very effective in distalizing maxillary molars, 
patient compliance and greater treatment time with the cervical headgear is necessary. Taner et $\mathrm{al}^{10}$ also observed that the indirect effect of the first molar distalization on unerupted maxillary second molars is the same with both appliances. ${ }^{10}$

In the second study, Mossaz et $\mathrm{al}^{11}$ found that the cervical headgear group experienced better molar tip back than the pendulum group. $5.08^{0}$ of distal root tipping was observed in the $\mathrm{CH}$ group and $1.9^{\circ}$ in the $\mathrm{P}$ group. Although the difference between the 2 groups $\left(3.18^{\circ}\right)$ was significant $(P<0.01)$, the authors did not consider it a critical factor in the choice of the cervical headgear or the pendulum appliance. Their findings were different from Taner et al, 10 probably because the values at $\mathrm{T} 2$ were registered after the full treatment, including fixed appliances. Therefore, Mossaz et $\mathrm{al}^{11}$ did not find loss of anchorage in the $\mathrm{P}$ group, like mesialization of premolars and incisors.

In the third study, when Polat-Ozsoy et $\mathrm{al}^{12}$ compared pendulum appliance to cervical headgear groups, they found that the latter had a greater amount of retrusion of the maxillary incisor in comparison to the former, without mesialization of incisors in the $\mathrm{P}$ group. They found that although cervical headgear had seemed to reduce anchorage loss and provided the most effective distal molar movement, the pendulum appliance can be an efficient method for distal molar movement without resulting in loss of anchorage.

The three studies ${ }^{10-12}$ were heterogeneous, but they concluded that the conventional cervical headgear has been frequently used to correct Class II malocclusion by restraining the forward growth of maxilla and by distalizing the maxillary molars into class I dental relationship. However, the success depends on the patient's compliance. On the other hand, the pendulum appliance is fixed, which does not rely on patient compliance and can distalize molars successfully, but probably it causes mesial movement of the first premolars and incisors. The loss of anchorage was found by Tanner et al. ${ }^{10}$

Several authors have stated that distal movement of the first maxillary molars is dependent on the stage of eruption of the second maxillary molars. ${ }^{18-21}$ For young patients, the best time to start therapy with a pendulum appliance is before the eruption of the second molars. If distalization of the first and second molars is to be carried out simultaneously, prior germectomy of the third molar is recommended..$^{22}$

Taner et $\mathrm{al}^{10}$ showed that the indirect effect of first molar distalization on unerupted maxillary second molars is also the same with both appliances. There were distal tipping and distal movement of the unerupted maxillary second molars in both groups similar to the angular changes in maxillary first molar tooth positions.

Mossaz et $\mathrm{al}^{11}$ and Polat-Ozsoy et $\mathrm{al}^{12} \mathrm{did}$ not consider that the eruption stage of the second molars has a qualitative and quantitative impact on first molar distalization. It means that the dental stage was not considered a limiting factor to start treatment in either group.

Several methods and scales to incorporate quality into systematic reviews have been proposed ${ }^{15,16}$ and have been applied to various RCTs. The quality of the articles was judge as low, medium or high according to a scoring system on the basis of the characteristics given in Table 4 .

In all studies, ${ }^{10-12}$ the methods to analyze maxillary dental changes were valid and well known. From a methodological standpoint, it was surprising that only one ${ }^{12}$ of the three studies declared the use of blinding in measurements. RCT with a blinding design is more likely to show the advantage an innovation has over a standard treatment method. ${ }^{23}$

The findings were conflicting because in the first ${ }^{10}$ study the mean amount of distal molar movement was similar in both groups, while in the second one ${ }^{11}$ the cervical headgear showed higher distal molar movement and distal tipping than the pendulum appliance. Polat-Ozsoy et al ${ }^{12}$ demonstrated significant maxillary incisor retrusion in the $\mathrm{CH}$ group without any maxillary incisor protrusion.

In conclusion, the reviewed studies showed that both cervical headgear with patient compliance and a noncompliance pendulum appliance are very effective in distalizing maxillary molars. However, additional RCTs with larger samples of both molar distalizing appliances are needed to confirm this result and provide further reliable scientific evidence.

\section{References}

1. Wieslander L. Early or late cervical traction therapy of Class II malocclusion in the mixed dentition. American Journal of Orthodontics and Dentofacial Orthopedics 1975;67(4):432-439.

2. Hilgers JJ. The pendulum appliance for Class II non-compliance therapy. Journal of Clinical Orthodontics1992;26(11):706-714.

3. Ghosh J, Nanda RS. Evaluation of an intraoral maxillary molar distalization technique. American Journal of Orthodontics and Dentofacial Orthopedics 1996;110(6):639-646.

4. Byloff F, Darendeliler M. Distal molar movement using the pendulum appliance. Angle Orthodontist 1997;67(3):249-260.

5. Jones RD, White JM. Rapid Class II molar correction with an open-coil jig. Journal of Clinical Orthodontics 1992;26(10):661-664.

6. Bondemark L. A comparative analysis of distal maxillary molar movement produced by a new lingual intra-arch $\mathrm{Ni}-\mathrm{Ti}$ coil appliance and a magnetic appliance. European Journal of Orthodontics 2000;22(6):683-695.

7. Needleman I, Moles D, Worthington H. Evidence-based Periodontology, systematic reviews and research quality. Periodontol 2005;37(1):12-28.

8. Montenegro R, Needleman I, Moles D, Tonetti M. Quality of RCTs in periodontology-a systematic review. Journal Dental Research 2002;81(12):866-870.

9. Hilgers JJ. The pendulum appliance for Class II non-compliance therapy. Journal Clinical Orthodontic 1992;26(11):706-714

10. Tanner T, Yukay F, Pehlivanoglu M, Çakirer B. A comparative analysis of maxillary tooth movement produced by cervical headgear and Pend-X appliance. Angle Orthodontist 2003;73(6):686-691.

11. Mossaz CF, Byloff FK, Kiliaridis S. Cervical headgear vs pendulum appliance for the treatment of moderate skeletal Class II malocclusion. American Journal of Orthodontics and Dentofacial Orthopedics 2007;132(5):616-623

12. Polat-Ozsoy O, Gokcelik A, Gungor-Acar A, Kircelli BH. Soft tissue profile after distal molar movement with a pendulum K-loop appliance versus cervical headgear. Angle Orthodontist 2008;78(2):317-323.

13. Dissemination. NCfRa. Undertaking systematic reviews of research on effectiveness. CRD's guidance for those carrying out or commissioning reviews. Available at: http://www.york.ac.uk/inst/crd/report4.htm. Accessed June 5, 2008.

14. Landis JR, Koch GG. The measurement of observer agreement for categorical data. Biometrics 1977;33(1):159-174. 
15. Antczak AA, Tang J, Chalmers TC. Quality assessment of randomized control trials in dental research. II. Results: periodontal research. Journal Periodontal Research 1986;21(4):315-321.

16. Jadad AR, Moore RA, Carroll D, Jenkinson C, Reynolds DJ, Gavaghan DJ et al. Assessing the quality of reports of randomized clinical trials: is blinding necessary? Control Clinical Trials 1996;17(1):1-12.

17. Cook A, Sellke T, Begole E. Control of the vertical dimension in class II correction using a cervical headgear and lower arch in growing patients Part I. American Journal of Orthodontics and Dentofacial Orthopedics 1994;106(4):376-388.

18. Cetlin $\mathrm{N}$, Ten $\mathrm{H}$. Nonextration treatment. Journal of Clinical Orthodontics 1983;17(4):396-413.

19. Gianelly AA. Distal movement of the maxillary molars. American Journal of Orthodontics and Dentofacial Orthopedics 1998;114(1):66-72.

20. Quick AN, Harris AMP. Molar distalization with a modified distal jet appliance. Journal of Clinical Orthodontics 2000; 34(3):419-423.

21. Fortini A, Lupoli M, Parri M. The first class appliance for rapid molar distalization. Journal of Clinical Orthodontics 1999; 33(2):322-328.

22. Kinzinger GSM, Fritz UB, Sander FG, Diedrich PR. Efficiency of a pendulum appliance for molar distalization related to second and third molar eruption stage. American Journal of Orthodontics and Dentofacial Orthopedics 2004;125(1):8-23.

23. Colditz G, Miller J, Mosteller F. How study design affects outcomes in comparisons of therapy. Medical Statement Medicine 1989;8(4):411-454. 